\title{
Discussion: Effects of granular columns in compacted fills
}

Vinayagamoorthy Sivakumar MSC, DIC, PhD, PGCHET Senior Lecturer, Queen's University Belfast, UK

Jane L. Boyd MEng, PhD

Lecturer, University of Ulster, Belfast, UK

Jonathan A. Black PhD, PGCHET

Lecturer, University of Sheffield, UK

James A. McNeill MSc(Eng), FGS, CGeol

Senior Engineer, Queen's University Belfast, UK
Colin J. Serridge EurGeol, CGeol, FGS, MIQ, MCIHT

Chief Engineer (Ground Improvement), Balfour Beatty Ground Engineering Ltd, Manchester, UK

Barry C. Slocombe MSc

Engineering Manager, Keller Foundations, Coventry, UK

Alan L. Bell PhD

Technical Consultant, Keller Group plc, London, UK

\section{Contribution by C. J. Serridge}

Sivakumar et al. (2010a) have presented some interesting laboratory-based research on wetting-induced settlement of fine-grained soils. However, there are several comments which this contributor would wish to make.

It is considered that it is misleading to state that 'the improvement method of vibrated granular columns is not commonly used in the treatment of fill materials'. Vibro-stone column techniques are one of the most commonly used ground improvement techniques in the UK, the principal application being for the treatment of heterogeneous fill materials on sites with a legacy of industrial activity (brown-field sites).

From an environmental sustainability view-point there is an increasing requirement for on-site retention of fill materials, particularly where cut and fill earthworks activity is required to achieve a development plateau, and this is mentioned in the paper. Inevitably this involves clay soils and suitable guidance exists on how such materials should be engineered in place (e.g. Specification for Highway Works (Series 600) (Highways Agency, 2009)) with accompanying guidance on monitoring, testing and quality control.

There are many sites where stone columns have been installed and performed perfectly satisfactorily in clay fills, including in historic 'un-engineered' clay fills and 'engineered clay' fills, for a range of applications, including low-rise housing and industrial units, within the UK.

Laboratory investigations do not replicate the true field condition in terms of calibration, scale effects and, in this case, the installation effects associated with a vibroflot (vibrating poker) displacement of the soil to form a vertical bore within which a compacted column of stone aggregate is constructed in small lifts to form a composite stone column-soil mass, with enhanced shear strength and bearing capacity, together with a corresponding reduction in settlement characteristics (attributed to the 'stiffening' effect of the stone columns). While the experimental study is described as preliminary and providing a direction for future investigations, it is important to recognise that field trials are an essential component of any future research if valid conclusions (applicable at the field scale) are to be made.

Deep back-filled former open-cast mining sites do require careful consideration and appraisal (in the context of vibro stone column techniques), where inundation-collapse settlement poses more of a risk, but where alternative ground improvement techniques can be considered (e.g. dynamic compaction), or measures implemented in conjunction with vibro stone columns to reduce the effects of this risk, dependent upon site-specific circumstances.

\section{Contribution by B. C. Slocombe and A. L. Bell}

The authors have presented a number of comments on wettinginduced settlements. The interest in the subject of how to treat this condition is to be welcomed. However, there are a number of issues with which these contributors would disagree. These are listed below.

(a) The statement that 'the improvement method of vibrated granular columns is not commonly used in the treatment of fill materials' is highly misleading. The authors are referred to Charles and Watts (2001), the Institution of Civil Engineers' Specification for Ground Treatment (ICE, 1987) and BRE's (2000) Specifying Vibro Stone Columns, all of which clearly discuss the use of stone columns to treat fill materials. It should be noted that the current BS EN ISO 14688-1: 2002 (BSI, 2002) now refers to such soils as 'Made ground' being either 'fill (controlled placement)' or 'reconstituted ground (uncontrolled placement)'.

Over the last 40 years, many hundreds of thousands, possibly in excess of one million, houses, offices, industrial units and so on, in the UK alone have been supported by vibro stone columns. While many of these projects involved the treatment of natural soils it has been assessed that in excess of $90 \%$ included the treatment of made ground, controlled fill, uncontrolled fill, reconstituted ground, non-engineered fills and/or engineered made ground, whatever the definition adopted. The contributors have considerable personal experience of successfully applying vibrated stone columns to such fills. Some of these developments, which were underlain by engineered and/or non-engineered fills, have been 
subjected to rising water table and flooding without any apparent distress, although it must be stated that the use of vibro stone columns does not claim to overcome the problem of collapse settlement.

(b) Among the key issues associated with drawing practical conclusions from model stone column tests that would assist engineers in practice is a clear need either properly to model or to correct for the material characteristics of the model soil and granular column material used. Allowance must also be made for the effects of installation and the scale effects, which for small models can be considerable.

(c) It is current practice to attempt to place controlled fill to $95 \%$ maximum dry density (MDD) or better. However, in many cases owing to factors such as variability in constituents, water content, particle size and so on, the post-compaction tests report $90-95 \%$ MDD being achieved. It is therefore clear that all of the laboratory soil materials employed in the study were 'engineered', regardless of the term 'unengineered' used. It is accepted that it is difficult to model the collapse settlement type soils properly in the laboratory to then be able to apply to full-scale susceptibility and the socalled collapse settlement of fills in engineering practice.

(d) The authors have attempted to produce a type of soil that is susceptible to collapse upon inundation using a kaolingranular mix and to provide a degree of stability when attempting to auger the bores for the model granular columns. Of course this auger operation in itself will affect the stress condition in the compacted test sample, to an extent which has not been measured. It is considered highly likely that disturbances induced during the installation of the test columns will adversely affect the results.

(e) Vibro stone columns in the field are designed to be relatively rigid in comparison to the surrounding soil. They derive their load-bearing capacity from a combination of internal angle of friction plus confinement arising from the surrounding soil by way of soil strength and overburden pressure. The reported bulk density of the test column material would suggest that granular drains rather than properly compacted granular columns have been constructed and tested.

$(f)$ The small-scale modelling of the single column test procedure adopted in the study means that the overburden pressure in the granular column is extremely low and that, with the size of the test footing being only marginally wider than the test column, rapid failure at minimal overburden pressure would take place. Consequently it is the case that the starting condition of the column is very much weaker in shear strength terms than the relatively heavily compacted soil in which it is embedded. This is the opposite of the situation in the field, where the overburden pressures beyond the usual footing depth enable a high strength relative to the surrounding soil. This effect significantly increases with depth. Full-scale vibrated stone columns also have the benefit of the vibratory compaction effect, which not only ensures high column density but also ensures the starting hoop stress in the column is relatively high. Taking all these factors into account the test results are entirely predictable, but sadly have no relevance for the practicing engineer.

(g) The referred Blanchfield and Anderson (2000) paper discusses the importance of overburden pressure when considering potential wetting collapse in opencast coalmine backfill, with particular reference to field monitoring data. Their figure 6 records negligible change in void ratio for compaction air voids of up to about $12 \%$. They also illustrate minimal change in void ratio on inundation occurring at low overburden pressures in their Figure 7. This Figure 7 is also presented by Trenter (2001) as applying to both weak rocks and cohesive fills. In contrast the authors have presented materials compacted to their optimum in the laboratory with significant collapse settlement occurring both with and without granular columns.

(h) It is accepted that the authors describe their paper as a 'preliminary experimental study' and these contributors suggest that further studies need to address the points raised. This includes dealing with scale effects by employing some means of modelling the confinement pressures both from overburden and from the vibratory compaction effect. A wider range of materials at different overburden pressures with assessed variation in change in void ratio, similar to the Blanchfield and Anderson (2000) and other published results, may prove helpful.

The authors' conclusions therefore arise from the limitations of the model testing approach adopted and do not at all reflect published field data or the contributors' own extensive experience in the overwhelmingly successful performance of vibro stone columns in fills in the support of real structures.

\section{Authors' reply}

The authors wish to thank Mr Slocombe and Dr Bell (Keller Group) and Dr Serridge (Balfour Beatty Ground Engineering Limited) for their constructive discussions on their paper (Sivakumar et al., 2010a). The content of the discussions clearly demonstrates the importance of the subject researched and its relevance to the ground improvement industry in general. All of the above writers comment on the fact that granular columns have been successfully used to treat compacted fills, and indeed they also acknowledge the fact that collapse settlement of uncontrolled cohesive fill (i.e. un-engineered fill) upon saturation is a major problem, and often other alternative ground improvement techniques are sought in such situations. The paper, although based on preliminary research, also draws the same conclusion. However, the authors acknowledge that the statement in the original paper 'vibrated granular column is not commonly used in the treatment of fill material' is misleading, but the intended message refers to un-engineered or uncontrolled cohesive fills. In response, the authors wish to summarise, first the typical behaviour of granular column applications and compacted fills separately, and second to make a collective study.

Compacted fills. Compacted fills are an essential part of engineer- 
ing construction and they are generally placed in a controlled manner, particularly when the end use of the filled ground is known (Boyd and Sivakumar, 2011). On the other hand, engineers also have to deal with reclaiming abandoned land previously backfilled using fills with or without control (Jarvis, 2011; Palmer and Wilson, 2011) and the nature of the placement is often unknown. The potential problems with un-engineered cohesive fills are perceived to be collapse settlement and loss of strength upon wetting. Palmer and Wilson (2011) make an interesting point that irrespective of the sources of the fill, it remains a young soil, and as such is susceptible to rapid change, the effects of which need to be assessed and controlled in the geotechnical design'. However, it should be noted that engineered cohesive fills (controlled fills) also exhibit significant heave upon wetting, particularly at low overburden pressures (Sivakumar et al., 2010b). Prediction of such responses of compacted fill is complicated largely by complex pore size distribution in which large saturated aggregates constitute the overall structure of the soils, and the macro voids between the large aggregates are filled with air and water.

Granular columns. Granular columns are widely used to improve the performance of weak deposits in order to reduce foundation settlement and to increase load-bearing capacity. The performance of granular columns depends entirely on the characteristics of the surrounding material. If the deposit is made of granular soil, the vibrating action during the formation of the columns will also densify the surrounding soils and it will indeed lead to enhanced overall performance. On the other hand, the installation process will not densify the surrounding soil if the soil is fine (silt and clay). In fact the installation process may weaken the existing strength of the soil owing to destruction of inherent structure. Also note that the overall success of granular column applications is dependent on the configuration of the foundation. For example, the manner in which the granular column contributes to the settlement reduction under a raft foundation is entirely different from that of a pad or strip foundation (isolated footing). For example, Black et al. (2011) reported settlement improvement factors of just over 2.5 for a $1.6 \%$ area replacement under a raft configuration and Sivakumar et al. (2011) reported a settlement reduction factor of 1.7 for an area replacement ratio of $44 \%$ under isolated footing. These settlement reduction values compare favourably with values reported by McCabe et al. (2009) based on numerous case histories. Based on field study in Bothkennar, Watts and Serridge (2000) conclude that granular columns did not reduce foundation settlement; however, an improved factor of safety against bearing capacity failure was achieved. These statistics clearly pose the question: are granular columns effective in treating soft clays?

Granular columns in compacted fill. The above paragraphs have summarised separately the subjects of granular column applications and compacted fill. Consider now how granular columns might behave in compacted fill. If granular columns are used in compacted fills of granular nature, they may not bring about any particular problems, where wetting-induced settlement is not significant and indeed the vibrating action will alone improve the surrounding soils. If the granular columns are used in compacted granular or cohesive fills (controlled or uncontrolled) for widespread loading (raft), then again potential problems with respect to settlement may not be significant. However, when granular columns are used for supporting isolated footings in cohesive fills (placed in an uncontrolled manner), this can lead to significant problems. Watts (2000) discusses the suitability of vibro columns for treating un-engineered cohesive fill, and concludes that collapse compression can be a serious hazard for buildings on fill. The saturation of fill will lead to reduced strength associated with collapse settlement, particularly at moderate to high overburden pressures. Both reduced strength and collapse compression are detrimental to the way the granular column functions under isolated loading (i.e. pad footing). On the other hand, if the granular columns are employed in engineered cohesive fill, although the reduction in strength may facilitate a bulging tendency, the swelling (or heave) upon wetting will lead to enhanced lateral stresses (Boyd and Sivakumar, 2011) and this will give added confinement to the granular column against bulging, making the granular column sustainable in treating fills placed in a controlled manner.

The authors would like also to make some further comments relating to particular points listed by contributors Slocombe and Bell. In item (c), they make a point that samples used in the present study are engineered, since the densities achieved for making samples fall within $90 \%$ of the MDD. It therefore clearly demonstrates the vulnerability of compacted cohesive fills under wetting, if the required initial conditions are not met during the initial placement.

Item $(d)$ refers to the stress condition in the sample due to augering and disturbances during column installation. Surely, the disturbance that may occur owing to the column installation in a pre-bored hole is much less than may prevail in full-scale field installations. In addition, the full-scale vibro application leaves some residual stresses in the column, which may utilise some of its bulging capacity.

Item (e) refers to the density of the column in comparison to the density of the surrounding soil. The density of the surrounding material reported in Figure 1 is bulk density; however, it had been reported as dry density. Dry density of the column achieved in the model study is approximately $1800 \mathrm{~kg} / \mathrm{m}^{3}$ (this density is referred to as bulk density in the original paper). The minimum density of the same material that was used for making the granular column is approximately $1500 \mathrm{~kg} / \mathrm{m}^{3}$. Therefore, the granular columns included in the model study are not mere vertical drains.

Item $(f)$ refers to the overburden pressure away from the footing, and this was about $6 \mathrm{kPa}$. This pressure correlates with standard CBR tests. The strength of the surrounding material is the main 
contributor to the bulging capacity of the granular column. A simple calculation using the method of Hughes and Withers (1974) shows that increasing the overburden pressure by $100 \%$ would lead to about $15 \%$ increase in bulging capacity. However, the authors agree that the strength of the soil will also increase with the overburden pressure, but it may not be the case in unengineered cohesive fills.

Item $(f)$ also highlights the benefit of hoop stresses in the column, generated by the vibro action. These hoop stresses are also accompanied by significant excess pore water pressure in the surrounding soil (caused by the vibro action). Surely, therefore, these hoop stresses are not permanent, and will reduce as the excess pore water pressure dissipates from the surrounding soil. Researches have made significant progress with respect to the prediction of settlement behaviour of compacted cohesive fills. However, at present there are no user-friendly predictive models for day-today applications. On that note, it is premature for the contributors to conclude that the results reported in the paper are predictable.

Item $(g)$ refers to negligible volume change (12\% air voids) at low overburden pressures. This is not surprising since wetting was carried out at low overburden pressure; however, on the other hand, to the best of the authors' knowledge, the material concerned in the study was 'mudstone', which can pose a serious problem during wetting under high overburden pressures.

The authors wish to thank all who have commented for showing interest in the study reported. Based on the reply, the authors conclude that application of granular columns in treating unengineered cohesive fills (under isolated footings) provides limited improvement and the problems discussed should not be ignored. The same may also apply to weak, natural clay-based deposits. Improvement of the performance of granular columns in such deposits would require carefully orchestrated field study, as suggested in the contribution by Serridge.

\section{REFERENCES}

Black JA, Sivakumar V and Bell A (2011) The settlement performance of stone column foundations. Géotechnique 61(11): 909-922.

Blanchfield R and Anderson WF (2000) Wetting collapse in opencast coalmine backfill. Proceedings of the Institution of Civil Engineers - Geotechnical Engineering 163(3): 139-144.

Boyd J and Sivakumar V (2011) Experimental observations of the stress regime in unsaturated compacted clay when laterally confined. Géotechnique 61(4): 345-363.
BRE (2000) Specifying Vibro Stone Columns. CRC Ltd, London, UK, BR391.

BSI (2002) BS EN ISO 14688-1: 2002: Geotechnical investigation and testing. Identification and classification of soil. Identification and description. BSI, London.

Charles JA and Watts KS (2001) Building on Fill. Geotechnical Aspects, 2nd edn. CRC Ltd, London, UK R424.

Highways Agency (2009) Manual of Contract Documents for Highway Works $(\mathrm{MCHW})$, Volume 1 - Specification for Highway Works (Series 600). Highways Agency, UK.

Hughes JMO and Withers NJ (1974) Reinforcing of soft cohesive soils with stone columns. Ground Engineering 7(2): 42-49.

ICE (Institution of Civil Engineers) (1987) Specification for Ground Treatment. Thomas Telford, London, UK.

Jarvis S (2011) Earthworks to reclaim Midland Quarry, for housing development. Proceedings of the Institution of Civil Engineers - Geotechnical Engineering 164(2): 79-87.

McCabe BA, Nimmons GJ and Egan D (2009) A review of field performance of stone columns in soft soils. Proceedings of the Institution of Civil Engineers - Geotechnical Engineering 162(15): 323-334.

Palmer JS and Wilson R (2011) Reclamation of former ironstone workings, Priors Hall, Corby. Proceedings of the Institution of Civil Engineers - Geotechnical Engineering 164(3): 235242.

Sivakumar V, Boyd JL, Black JA and McNeil JA (2010a) Effects of granular columns in compacted fills. Proceedings of the Institution of Civil Engineers - Geotechnical Engineering 163(4): 189-196.

Sivakumar V, Sivakumar R, Murray JE, Mackinnon P and Boyd J (2010b) Mechanical behaviour of unsaturated kaolin (with isotropic and inisotropic stress history). Part 1: wetting and compression behaviour. Géotechnique 60(8): 595-609.

Sivakumar V, Jeludine DK, Bell A, Glynn D and Mackinnon P (2011) The pressure distribution along stone columns in soft clay under consolidation and foundation loading. Géotechnique 61(7): 613-620.

Trenter NA (2001) Earthworks: A Guide. Thomas Telford, London, UK.

Watts KS (2000) BR391: Specifying vibro stone columns, Section NGI 3.2. Building Research Establishment, Watford, UK.

Watts KS and Serridge CJ (2000) A trial of vibro bottom-feed stone column treatment in a soft clay soil. Proceedings of the 4th International Conference on Ground Improvement Geosystems - Grouting, Soil improvement and Geosystems Including Reinforcement, Helsinki, 7-9 June. Building Information System, Helsinki, Finland, pp. 549-556. 